\title{
O sertão educa
}

\author{
Gilmar Leite Ferreira \\ Universidade Federal da Paraíba \\ Terezinha Petrucia da Nóbrega \\ Walter Pinheiro Barbosa Junior \\ Universidade Federal do Rio Grande do Norte
}

\section{Resumo}

O presente artigo caracteriza a relação homem e natureza, apresentando o sertão nordestino como um lugar que educa. Fundamentado na filosofia de Merleau-Ponty, o trabalho temcomo objetivo mostrar a educação do sertanejo, fruto da experiência vivida, em um lugar onde o processo de aprendizagem é constante, expressandouma educação tecida na vida do sertanejo por meio de uma natureza imprevisível, indeterminada e que está sempre em transformação. Por intermédio do método fenomenológico, interpreta-se o fenômeno educação, sem fechá-lo em um conceito, mas tomando-o em um horizonte de sentidos.

Palavras chave: Educação. sensível. Sertão. Fenomenologia.

\section{The hinterland education}

\section{Abstract}

This paper characterizes the relationship between man and nature, presenting the Northeastern hinterland as a place that educates. Based on Merleau-Ponty's philosophy, the study aimed to show the education of the backcountry man, result of his lived experience, in a place where the learning process is constant, expressing an education woven into the life of the backwoodsman by an unpredictable, indeterminate and ever changing nature. We interpret the education phenomenon through the phenomenological method without closing it into a concept, but taking it in a horizon of senses.

Keywords: Sensitive education. hinterland. Phenomenology. 
Gilmar Leite Ferreira | Terezinha Petrucia da Nóbrega | Walter Pinheiro Barbosa Junior

\section{El interior educa}

\section{Resumen}

En este artículo se caracteriza la relación entre el hombre y la naturaleza, que presenta el interior del noreste como un lugar que educa. Sobre la base de Merleau-Ponty, el trabajo pretende mostrar la educación de la travesía, el resultado de la experiencia vivida, en un lugar donde el proceso de aprendizaje es constante, expresando una educación entretejido en la vida del hombre de la frontera a través de una naturaleza impredecible, indeterminado y que siempre está cambiando. A través del método fenomenológico interpreta el fenómeno educativo, sin cerrar en un concepto, pero tomarlo en un horizonte de sentido.

Palabras-clave: Educación sensibles. Interior. Fenomenología.

\section{Introdução}

Entre os espinhos dos cactos vorazes e das juremas agressivas; sob um sol inclemente, abrasador e causticante; embevecido pelas águas das chuvas, córregos, rios, açudes e lagoas; sobre os cascalhos e os tocos pontiagudos; acariciado pelas flores perfumadas, pelas asas de seda das borboletas multicores e pelos cantos dos pássaros; o sertanejo se faz terra e se transforma no imenso corpo do sertão. Envolto de esperança e desilusão, mergulha em si mesmo, procura o equilíbrio da existência diante de uma natureza impiedosa e acolhedora, a qual afeta a sua vida sensível com os movimentos, cores e sons da caatinga.

Atordoado pelas contingências dos dias vindouros reinventa-se a todo instante; adapta-se, constrói relações com os vegetais, minerais e os outros animais; elabora a beleza da expressão artística, por meio de uma cultura diversificada e vive na eterna busca de um sentido de convivência compartilhada, num lugar onde os excessos e as faltas fazem parte do cotidiano.

Essa terra paradoxal é o sertão nordestino; um lugar repleto de incertezas, encantamento e movimento, e, por isso, provoca o sertanejo a se reinventar a todo instante, sempre buscando novos aprendizados, diante de uma vida em constantes desafios.

Para trilharmos no sertão em busca da compreensão de um lugar que educa, fez-se necessário assumir uma atitude fenomenológica, tendo o cuidado 
de não nos acostumarmos com o objeto pesquisado, mas sim, colocá-lo numa suspensão, ficar alheio a sua forma imediata de ser, olhá-lo como se fosse uma primeira vez, assumindo um contato "ingênuo" em busca de um horizonte de sentidos, sem jamais transformá-lo numa ideia, porém sim, num lugar que se estende a cada compreensão e que vive sempre em movimento (MERLEAUPONTY, 1999). Por isso, nossa alma sertaneja e o entusiasmo de pesquisadores nos permitiram caminhar nas trilhas sertanejas, dialogando com diversos autores que inspiraram os procedimentos metodológicos necessários, para que se caminhasse em busca da compreensão do sertão como um lugar que educa.

Tendo como aporte a filosofia de Merleau-Ponty, mas precisamente, os livros, A Natureza (2006) e a Fenomenologia da Percepção (1999), o artigo tem, como referencial, a noção de natureza, de algo que está na origem, antes de uma formulação ou ideia, e a fenomenologia como: movimento, expressão e o entrelaçamento do homem no mundo da vida.

A pesquisa objetivou interpretar a educação do sertãoe, identificou que ela se faz presente nas coisas do sentir, do pensar e do movimentar-se, expressando o entrelaçamento do homem com o sertão por intermédio da experiência vivida.

O sertão propõe ao homem uma educação tecida na existência sensível, aprendida e apreendida pelas relações constantes entre o homem, a cultura e a natureza, num lugar onde tudo está entrelaçado, fazendo da existência um caminho, em que, a cada passo, a cada horizonte, há sempre um novo sentido'.

É uma educação corpórea, pois ela amplia as luzes dos sentidos humano para uma contínua maneira de perceber o que compõe o sertão. Essa educação se amplia no campo das relações entre homem, natureza e cultura. Ela abre o horizonte da compreensão de uma relação de sujeito para sujeito, ligandoa existência pelos fios de uma convivência permanente, e se realiza por meio das relações, sempre em busca de uma aproximação maior entre a interioridade humana e o que está no mundo percebido.

Apresenta-se, neste estudo, o sertão nordestino. Essa escolha está pautada no campo de uma natureza repleta de aporias e contingências, em que o bioma caatinga representa a expressão de uma natureza imprevisível, onde as estações de chuva (inverno) e verão (ou seca) estão impregnadas na existência do sertanejo, proporcionando uma aprendizagem repleta de transformação, de acordo com os ritmos da vida. Por isso, o sertão nordestino, mostra-se pautado 
em um movimento constante de transformação, o qual remete a reflexão de uma educação impregnada de novas experiências.

sertão nordestino, como um espaço geográfico, um estado de espírito, uma condição sensível e uma expressão cultural, tem, na vida animal e vegetal, uma natureza distinta que forma os elementos simbólicos da cultura, manifestados na forma de ser, de pensar, de agir, de sentir e de mover-se, como uma condição existencial que mostra a relação do homem com a terra.

Por ter uma natureza única, revelada por intermédio da caatinga, o sertão nordestino não é algo dado à pura contemplação ou a fundação de uma ideia. Os ecos da caatinga, os movimentos dos animais, o cair das águas, as longas estiagens, as relações humanas, as expressões da cultura, os signos da interação homem-natureza, formam todo um corpo de vida, compartilhada entre todos os seres do mundo sertão. É um lugar que aproxima e afasta, assusta e causa encanto, parece estático, mas não para de se mover, de se reinventar e de expressar a ontologia de um Ser, constituído pela relação homem e natureza, fundando uma expressão cultural, repleta de ensino e aprendizagem.

No sertão nordestino, a existência corpórea do sertanejo se amplia e se reinventa a todo instante. A aridez ou a invernada tornam-se corpo na vida do sertanejo, e a condição sensível, dimensiona a vida para um estado uno entre os seres que habitam o mundo-sertão. Nesse sentido, o corpo do sertanejo é a terra fértil onde florescem, se relacionam e convivem as coisas que estão presentes na natureza e na cultura. A percepção dilata o sentido corpóreo e podemos perceber o sertanejo sendo árvores, outros animas, vales e serra. Essa transubstanciação mostra que o corpo do sertão e o do sertanejo, tornam-se campos de uma mesma linguagem (MERLEAU-PONTY, 1999).

$\bigcirc$ corpo do sertanejo se reinventa diante de uma vida repleta de ciladas, onde cactos, juremas, galhadas, flores, espinhos, secas, chuvas, impulsionam diversas maneiras de o sertanejo se mover, pensar e sentir. $\bigcirc$ corpo quasímodo ou hercúleo do sertanejo (CUNHA, 2002) convive entre os extremos de uma natureza agressiva e, ao mesmo tempo, afetuosa. Esse mundo adverso explode na paisagem e na vida do sertanejo, e não podemos separá-lo porque eles estão entrelaçados, configurados nas dobras da sensibilidade humana e da natureza sertaneja. Por isso, não devemos compreender a natureza aquém do humano. (MERLEAU-PONTY, 2006). 
"A Natureza é um objeto enigmático, um objeto que não é inteiramente objeto; ela não está inteiramente diante de nós" IMERLEAU-PONTY, 2006, p. 4), mas sim, está no entorno e dentro de nós, no objetivo e no subjetivo, aberta à experiência sensivel que se amplia numa dimensão repleta de sentidos, os quais estão sempre se renovando para novas configurações. Portanto, a natureza mostra-se como um Ser Selvagem², revelado como o Ser da criação. O Ser Selvagem se faz presente no não dito; ele abre a possibilidade para criação de sentidos e reflete o que ainda não foi pensado, podendo abrir espaços para outros dizeres, bem como para a elaboração de significados que ainda não foram formados (MERLEAU-PONTY, 2000).

Nesse sentido: [...] "é Natureza o primordial, ou seja, o não construído, o não instituído" (MERLEAU-PONTY, 2006, p. 4). Essa afirmação nos remete a algo que está na origem, antes de qualquer formulação; portanto a natureza antecede o pensamento objetivo e se faz presente como um Ser Selvagem.

Podemos compreender que "A Natureza é o nosso solo, não aquilo que está diante de nós, mas o que nos sustenta" (MERLEAU-PONTY, 2006, p. 4). Nessa concepção, interpreta-se a natureza como a solidez de se fazer presente no mundo, não como uma coisa que está a nossa frente para ser objetivada. Ela 194 é o que nos envolve com seu espetáculo de forma imprevisível. "A natureza é um princípio de significações. Ela é o grande referente, o princípio da realidade que estrutura a produção e recorta significados" (MEYER 2008, p. 28).

A criação de sentidos mostra que a natureza sempre revela significações por intermédio das cores, da subjetividade dos animais, da flora, dos movimentos, dos horizontes de sentidos e das ampliações de expressões sensíveis. Assim, revela sua maneira de ser, bem como a expressão ${ }^{3}$ do humano nas suas diversas formas de existência, ampliando o sentido da vida, revelada no que a natureza tem de mais singular e plural ao mesmo tempo.

A Natureza é diferente, portanto, de uma simples coisa; ela tem um interior; determina-se de dentro; daí a oposição de 'natural' e de 'acidental'. E não obstante a Natureza é diferente do homem; não é instituída por ele, opõe-se ao costume e ao discurso (MERLEAUPONTY, 2006, p. 4).

Por ser algo que não podemos conquistar por intermédio do entendimento puro, instituindo-a, como algo pronto e inteiramente perceptível, a natureza, esconde-se entre as rochas da compreensão fechada e do pensamento 
objetivo. Sua textura entrelaça-se com o humano por meio de uma configuração de algo móvel e expressivo, revelando novas configurações, mostrando diversas maneiras de ser. A natureza não repousa, somente, no humano ou no ambiente, por isso ela é um Ser ${ }^{4}$ em movimento que entrelaça ambos, revelando-se como expressão criativa.

A compreensão da natureza possibilita um encontro consigo mesmo. Esse encontro mostra a natureza como um Ser em transubstanciação, impulsionada por sua identificação com o humano, compreendendo-a como a nossa própria existência, conforme a afirmação do filosofo francês, vejamos:

Para reencontrar o sentido da Natureza exterior, cumpre fazer um esforço, a fim de reencontrar a nossa própria Natureza no estado de indivisão em que exercemos a nossa percepção: na medida em que sou idêntico à Natureza, compreendo-a tão bem como a minha própria vida (MERLEAU-PONTY, 2006, p.63).

Compreendermos a nós mesmos e o mundo unifica a existência com as coisas que estão em nós e em nosso entorno. Esse entrelaçamento dimensiona o humano aos aspectos da cultura, na qual estamos imersos, como seres históricos e corpóreos. Os signos da cultura representam a nossa condição de sujeitos em constantes diálogos, na elaboração de códigos e símbolos construídos pela relação entre sujeitos, fundando sempre novas expressões no campo da intersubjetividade, a qual se realiza no intermundo (MERLEAU-PONTY, 1999). O mundo vivido se expressa na intercomunicação do

[...] ser-no-mundo, na ordem do que é vivido e não do que é pensado, pois o sentir é pré-objetivo. Isso se dá pela relação 'eu, o outro e as coisas' em estado nascente, admitindo uma expressão vital primordial, que desencadeia numa relação ontológica do corpo (REIS, p. 106, 2008).

Por meio da expressão cultural, o sertanejo se faz sertão. Esse diálogo revela a condição do sertanejo como um ser da cultura do seu lugar, onde a maneira de pensar, de agir, de seexpressar e de se comunicar, mostra os costumes e a forma de ser do homem sertanejo. Os elementos da cultura são o grande amálgama do sertão. Eles estão sempre em movimento e fazem o sertão "andar" e se fazer presente em outros lugares. 


\section{A educação do sertão}

A educação do sertão, por meio de uma concepção fenomenológica ${ }^{5}$, abre-se para o mundo das relações sensíveis, onde a vida mostra-se impregnada de signos ${ }^{6}$. Nessa concepção, ela sealoja nos músculos, nos ossos e nos nervos, movendo a maneira do homem pensar e viver; ensina como a natureza se revela e se recolhe, a qual, muitas vezes, explode na paisagem e na vida, outras vezes se cala e fica em silêncio para novas expressões. A educação do sertão mostra-se na existência como um eterno expressar de aprendizados e convivências.

Os fios da cultura sertaneja se fazem de várias significações e tecem o pano da pluralidade dos sentidos de que as relações humanas, animais e vegetais se impregnam. A cultura do sertão, com toda a sua plasticidade, borda o tecido da vida por meio de elaborações sensíveis que são vividas no dia a dia, interligando os seres do sertão.

É uma cultura que emerge da natureza, infiltra-se no sentimento sertanejo e se expressa nas mais diversificadas maneiras de realizar-se. $\bigcirc$ canto de um pássaro, a paisagem, as festividades, a arte poética, musical, teatral, visual e outras expressões do homem, fundam um logos estético 7 e cultural, externados 196 em formas de expressões culturais que desenham no sensível as maneiras de ser do povo sertanejo. É nas relações corpo e mundo ${ }^{8}$ que a existência é bordada com as cores da cultura.

Corpo e mundo são um 'campo de presença' onde emergem todas as relações da vida perceptiva e do mundo sensível. Há um logosdo mundo estético, um campo de significações sensíveis constituintes do corpo e do mundo. É esse logos do mundoestético que torna possível a intersubjetividade como intercorporeidade, e que, através da manifestação corporal na linguagem, permite o surgimento do logos cultural, isto é, do mundo humano da cultura e da história (CHAUÍ, 1989, p. X).

mundo da vida, com suas indeterminações, contingências e aporias, abre o leque da existência, impregnada de aberturas, sem sefechar na opacidade do pensamento, alheio às coisas do sentir. $\bigcirc$ mundo está sempre aberto, impregnado de ações, de movimentos e de interligação entre os seres vivos (MERLEAU-PONTY, 1999). 
Cada movimento do sertão está intrinsecamente relacionado com as expressões do sertanejo, fazendo da existência de ambos um amálgama de convivências, em que o respeito, o amor e a admiração do homem pelas coisas do sertão, são manifestações de uma educação vivida no corpo e na compreensão do sertanejo sobre uma terra que, mesmo na contingência, na imprevisibilidade e na indeterminação, afeta a existência humana, tornando-a mais sensível e aberta às transformações.

A expressão do sertão como um lugar que educa é dimensionada pelo mundo vivido?. Essa noção mostra que as coisas no sertão estão ligadas umas as outras pelos fios das relações sociais, culturais, educacionais, afetivas e da natureza como um todo; cada uma revelando sua maneira de ser. Nessa concepção, podemos sugerir que as coisas se fazem presentes antes de qualquer formulação ou ideia.

A educação sertaneja não comporta em si um sujeito isolado do mundo, nem o mundo alheio a si. Ela seenraíza na relação, nas trocas, na convivência, no entrelaçamento, na impregnação de signos do sertão na existência humana, dilatando o fluxo da vida para realização de novas aprendizagens. $\bigcirc$ mundo vivido e percebido está sempre se infiltrando na existência, mesmo antes de um entendimento puramente mental. É o mundo pré-reflexivo, o qual não é classificado pelo sujeito nem fundado na pura exterioridade do objeto (MERLEAU-PONTY, 1999).

A noção mundo vivido mostra que a experiência vivida se realiza nas constantes trocas entre o homem e o sertão, construídas no dia a dia, em que a vida, na sua forma de ser, vai sendo elaborada pelos caminhos da relação sujeito/sujeito, fazendo do cotidiano um novo sentido, em que o homem aprende com a natureza, e mostra por intermédio do aprendizado a sua transformação.

No sertão, cultura e educação são fios de um mesmo tecido. Esses dois campos de significações estão sempre se renovando por meio da elaboração e reelaboração, como se tudo estivesse sempre começando. Por isso, os sentidos e significados estão sempre se fazendo presentes de outras maneiras.

No campo do sentir, do saber e da cultura, brota o entrelaçamento do humano com o mundo. $\bigcirc$ quiasma ${ }^{10}$ configura-se entre as dobras do objetivo e do subjetivo, na interseção do encontro; e se realiza na reversibilidade, fundando sempre uma nova expressão. Ele é a ligação do vidente com o visível, onde as coisas se apalpam se interpenetram num cruzamento de acontecimentos, 
sem hierarquias nem determinações. Os fios da vida, repletos de significações, ampliam o entrelaçamento para a realização do que ainda não aconteceu e pode criar horizontes de sentidos (MERLEAU-PONTY, 2000).

O entrelaçamento entre natureza e humano constitui-se na passagem da animalidade para a realização da cultura, por meio da expressão, ampliando a existência; partindo de um zero para a realização do que ainda não foi vivido e percebido. $\bigcirc$ entrelaçamento aproxima mundos, desvela sentidos, constrói significados e abre novas percepções do humano sobre si mesmo e o mundo que o cerca.

Assim como há uma reversibilidade daquele que vê e daquilo que é visto, assim como no ponto em que se cruzam duas metamorfoses nasce o que se chama percepção, assim há, também, uma reversibilidade da fala e do que ela significa; a significação é o que vem selar, fechar, reunir a multiplicidade dos meios psíquicos, fisiológicos, linguísticos da elocução, contraílos num ato único, como a visão termina o corpo estesiológico; e tal como o visível capta o olhar que o desvendou e que dele faz parte, repercute nos seus meios, a significação anexa a si a fala que se torna objeto da ciência, antedata-se por um movimento retrógado, nunca completamente falho, porque já, ao abrir o horizonte do nomeável e do dizível, confessava a palavra ter aí o seu lugar, porque nenhum locutor fala sem antemão transformar-se num alocutório, ainda que apenas de si próprio, sem fechar com um só gesto o circuito de sua relação consigo e com o outros, e ao mesmo tempo instituir-se também como delocutório, fala de que se fala -: Ele se oferece toda a fala a uma Palavra universal (MERLEAU-PONTY, 2000, p. 148-149, grifos do autor).

Como os galhos das árvores se cruzam, abraçam-se e se entrelaçam para a formação da copa, o quiasma natureza, humanos e cultura, interliga para a constituição de uma simbiose que alimenta a existência de cada um e transcende um existir compartilhado de trocas e cooperações, formando a copa da existência. $\bigcirc$ quiasma amplifica a natureza, a cultura e o humano pelos fios da objetividade e da subjetividade, criando uma intersubjetividade e despertando no humano o sol de uma sensibilidade que o liga aos outros animais e vegetais. $\bigcirc$ entrelaçamento sensível do humano com a natureza faz eclodir do corporal: sensações, emoções, afinidades, afetos, respeito e amor pela força da atração sinestésica que a natureza tem em afetar a existência humana. Essa 
relação afetiva faz emergir do humano uma educação experimentada de forma sensível, vivenciada no corpo e na compreensão de que a natureza está tanto no entorno como no corpo humano.

É no abraço entre o sertão e os seres vivos que o compartilhamento da vida é realizado para a fundação ${ }^{11}$ de uma expressão a qual se diz muito da natureza. Ele surge por meio do afeto e do compartilhar da busca de uma verdade dialogada, pelo entrelaçamento de tudo o que está posto no sertão. Nesse sentido, pode-se perceber que a vida no sertão se realiza num grande abraço.

O abraço é a aptidão para empreender a partilha, o consolo, a solidariedade e o afeto. Abraçar é prover, pela relação dos corpos, a dialógica dos espíritos. Por vezes, entretanto, o abraço prescinde a própria matéria, e podemos falar, sem exageros, que abraçamos ideias, utopias, projetos políticos, esperanças (ALMEIDA, 2000, p. 211.

entrelaçamento natureza, humanos, educação, constitui-se num abraço para a seiva da vida. Cada sentido que se expressa no humano pelo seu envolvimento sensível com a natureza é um fluxo da vida, um impulso que move o viver sempre de forma renovada, transformando a existência a cada contato do humano com a natureza, despertando o encantamento com o lugar ondeestá inserido.

\section{Os encantamentos do sertão}

Como expressão sensível, o sertão é um lugar de encantamento. Nele, a natureza bela e assustadora toca o sentimento sertanejo e faz emergir um ser humano profundamente admirado com a natureza. A florada da jurema, o canto seresteiro de um tenor sabiá, a delicadeza de um beija-flor, o pôr-do-sol avermelhado na abóboda celeste, a agressividade dos espinhos dos cactos: são momentos de encantamento que tocam a sensibilidade do sertanejo, despertando no sensível um profundo estado de devaneio e admiração. A expressão do sertão borda os sentidos com sua força de atração pelo que tem de mais primordial.

A força magnética do sertão desperta e revela um encantamento estético num movimento de sentidos que aproximam os humanos com outros animais. 
Ela amplia a abertura do sensível proporcionando o sertanejo a se aproximar dos animais, a ser parte deles, desvelá-los pelo viés de um logos estético. $\bigcirc$ sensível nos leva a conhecer e compreender o que está oculto, do outro lado das coisas, sem precisarmos positivamente instrumentá-lo, mas, sim, penetrar na sua espessura e vivê-lo (MERLEAU-PONTY, 1999).

Para refazermos nossa relação com a natureza, é preciso que nos sintamos como seres da natureza em toda a sua amplitude. Por isso, precisamos rever o nosso contrato animal, ou seja, como nos comportamos dentro da imensa cadeia biológica dos seres vivos e qual é o nosso papel na natureza. Ao longo dos tempos, atrelados ao pensamento sujeito/objeto, temos nos apossado da natureza, como se esta fosse algo a ser usado e não tivesse relação com nossa existência.

A quebra do Contrato Animal tem sido desastrosa de duas maneiras distintas. Em primeiro lugar, rompeu a complexa rede biológica de formas de vida neste planeta. Ela tem sido abalada e desfigurada de tal forma que agora existem sérios riscos de crise de alimentação, formas de epidemias e um colapso nos ciclos de vegetação. Pode ser que nos transformemos nos maiores construtores de desertos da história. Além disso, esse rompimento nos deixou tão longe de nossos companheiros animais que já não raciocinamos de maneira biológica. Já não percebemos que necessitamos de soluções biológicas para muitos de nossos problemas: não soluções químicas, matemáticas ou até políticas, mas soluções animais, pois nós somos animais (MORRIS, 1990, p. 14-15).

Reconhecermos a nossa condição animal possivelmente seja o nosso reencontro com a natureza, pois essa religação restitui nossa compreensão de que podemos aprender com outros seres vivos. Nessa configuração de convivência, a expressão do sertão constrói um elo entre o homem e os demais animais, haja vista que a concepção, humano e natureza, como dois fios de uma mesma existência, amplificam o sentido de sertão para uma realização fundamentada nas trocas e cooperações, tendo assim a costura do sensível como uma tecelã para fundação do sertão como um campo de educação.

Por meio da expressão, o sertão é uma explosão sensível na qual eclode do profundo uma diversificada natureza, distinta em seus momentos adversos que demonstram ora uma paisagem verde e exuberante, ora uma aridez desértica e assustadora. Mas, em ambos os momentos, o sertão expressa um Ser 
sensível por meio do seu corpo num turbilhão de movimentos, repletos de signos e símbolos ${ }^{12}$, os quais vivem abertos para elaborações sensíveis. Seu lócus penetra nos recantos latentes da existência dos seres vivos e constrói relações num entrelaçamento corpóreo, revelando a vida de maneira variada.

Podemos perceber na caatinga as adversidades de uma natureza que funda a cultura sertaneja, expressando novas manifestações estéticas. Como a natureza se reinventa, criando sentidos, os humanos do sertão também estão mostrando outras formas de ser, mesmo quando a vida se encontra nas incertezas e nas contingências. Do mesmo jeito que, a caatinga revela-se na sua diversidade, o sertanejo se mostra de maneira distinta, fundando, constantemente, uma nova expressão que diz muito de si e do mundo vivido.

O domínio da caatinga é, desta forma, extremamente diversificado em tipos de paisagem: serras de média altura, rios com drenagem intermitente, encostas pedregosas, depressões, áreas semidesérticas, encraves com maior umidade e com variação latitudinal bastante nítida (Maranguape, Baturité). Tudo isso, somado à tipicidade do homem regional em sua maneira de vestir, de morar, de deslocar-se em suas culturas, em seus animais domésticos e nos instrumentos de pesca e de captura de animais (arapuca), empresta à caatinga, tanto no segmento natural quanto no social, o caráter de uma região de eleição para a diversidade que prende e encanta o visitante (MELLO FILHO, 1995, p. 27).

Provocado pelo encantamento, o sertanejo, ou visitante, sente a aproximação que penetra no orgânico, mexe em cada célula, excita o sistema nervoso, amplia a concepção de mundo vivido, causa-the uma leveza de amor e admiração pelo sertão. Essa relação intrínseca eleva a existência do sertanejo, fazendo-o buscar no movimento da natureza um aprendizado pela relação com o mundo vivido para uma melhor convivência.

O sertão, como um Ser sensível, tanto se faz presente no humano como se faz na natureza. Ele está intrinsecamente ligado ao mundo da objetividade e ao da subjetividade. Nesse sentido, o antropólogo Claude Lévi-Strauss nos diz:

É verdade que também traduzo 'sertão' por brousse (mato). $\bigcirc$ termo tem uma conotação um pouco diferente. 'Mato' refere-se a um caráter objetivo da paisagem: a brousse, no seu contraste com a floresta; ao passo que 'sertão' refere-se ao aspecto subjetivo; à paisagem em relação ao homem (LÉVI-STRAUSS, 1996, p. 151 ). 
Podemos perceber, na citação de Claude Lévi-Strauss (1 996), que as dimensões do sertão se entrelaçam e forma um corpóreo sensível que faz da existência um caminho aberto para uma revelação expressiva, pelo fazer e refazer da vida, o começo e o recomeço, nas quais o outro não se encontra isolado, mas sim fazendo parte de um mesmo mundo, onde as adversidades se encontram, dialogam, ampliam-se, abrindo caminhos para construções de signos.

A dimensão sensível do sertão vai muito além do que imaginamos ou podemos compreender. Não é um estado de consciência isolado do mundo, mostrada numa transcendência, resumida em si mesma; é o envolvimento com o espetáculo da experiência vivida, num entrecruzamento de vidas em diálogos constantes.

O 'sertão' acaba sendo toda uma confusa e tumultuada massa do mundo sensível, caos iluminado que só uma ínfima parte nos é dado a conhecer, precisamente o que nos avista ao longo das 'veredas', tênues canais de penetração e comunicação (RÓNAl, 2006, p. 16).

As elaborações do sertão estão sempre se renovando, movimentando202 -se nos canais do seu corpo expressivo e se transubstanciando pela textura de ligações de vidas distintas. No sertão, tem-se a impressão de que as coisas estão começando, como se nunca existissem, mas, de repente, tudo muda, e sepercebe a revelação posta como configurações existentes de um corpo sensível que sempre existiv e não se esgota.

No sertão, as cores se combinam, misturam-se, afastam-se, expressando os tons dos animais, minerais e vegetais numa semelhança que mostra a tinta do pincel da natureza pintando todo o corpo da terra. $\bigcirc$ mimetismo não é, apenas, um quiasma da vida se preservando ante a ameaça da sobrevivência ou do aniquilamento, mas é também, um entrelaçamento de corpos misturados numa semelhança que amplia a expressão.

A relação do animal com o meio é uma relação física, no sentido estrito da palavra? A questão é justamente essa. O que o mimetismo parece, pelo contrário, estabelecer é que o comportamento só se pode definir por uma relação perceptiva e que o Ser não pode ser definido fora do ser percebido (MERLEAU-PONTY, 2006, p. 307). 
Ao olharmos o campo de expressão do sertanejo, podemos perceber o corpo do sertão, revelado nas rugas, na maneira de andar, sempre de forma incerta, nos gestos, nos cantos e em outras dimensões sensíveis. Sem nenhum determinismo biológico ou cultural, mas sim, pelo viés de uma compreensão sensível, o sertanejo e o sertão se configuram na aparência, dando impressão que ambos são feitos do mesmo tecido, expressando um mimetismo de cores, movimentos e sons.

A Natureza é aquilo com que tenho uma relação de caráter original e primordial, é a esfera de todos os 'objetos que podem ser apresentáveis originalmente e que, pelo fato de que são apresentáveis a um determinado sujeito, o são a todos os outros', ou 'a Natureza é a totalidade dos objetos possíveis apresentáveis originalmente, os quais, para todos os sujeitos originalmente comunicantes, constituem um domínio de presença originária comum' É a natureza matéria espaço-temporal... $\bigcirc$ único mundo para todo mundo (MERLEAU-PONTY, 2006, p. 153).

Cada movimento da natureza mostra a vida interligada pelas cooperações dos seres vivos, tanto na natureza do sertão, como na natureza de outras regiões, pois nada se encontra isolado e preso a uma ideia objetiva. A terra ensina aos humanos, e estes, mergulham no seu ventre, esposam o solo, fecundam seu útero por intermédio das plantações dos frutos, os quais servirão a si próprios e aos seres que habitam o mesmo espaço geográfico. A simbiótica relação dos humanos com os outros animais e plantas amplifica-se numa educação de respeito pela terra e pelos seres vivos.

Período das chuvas, verão ou seca, movimenta no sertanejo o sentimento de afeto e de dúvida em relação a uma terra adversa, mas que encanta independente de como se mostra. Por isso, as maneiras de o sertão se expressar sensivelmente estão entrelaçadas com a do humano ao serevelar esteticamente. "O ambiente/sertão não está separado das pessoas, dos bichos e das plantas, e sim, dentro de cada um, caracterizando o jeito de ser e de viver" (MEYER, 2008, p. 1931.

Podemos compreender que o sertão não é uma ideia construída pelo pensamento objetivo, mas, como um Ser sensível em movimento, moldando a existência humana para diversas configurações de ser e de estar no mundo; não como um sentido de causa e efeito, mas como uma relação de inerência que existe entre ambos. "As dificuldades de compreensão da ontologia do sertão, 
com suas ambiguidades, ambivalências, contradições, paradoxos e aporias são do mesmo caráter das que se referem à condição humana" (MELO, 2006, p. $114)$.

A vida no sertão acontece de maneira sensitiva e envolvente. Cada pedaço da terra é um pedaço do sertanejo, e quando ela sofre, os seres vivos sofrem juntos, numa relação de cumplicidade, como os galhos de uma mesma árvore. Viver no sertão é desenvolver uma capacidade inexorável de estar ligado por um elo onde a vida está sempre provocando novas formas de convivências e reinvenção de si mesma. No corpo do sertão, encontram-se os movimentos sensíveis explodindo na paisagem e por dentro dos seres vivos, revelando diversas manifestações da natureza, nas quais a vida flui de forma paradoxal e,ao mesmo tempo, harmoniosa.

Todos os seres vivos comungam o mesmo chão, ar e água do sertão lé uma intensa e borbulhante vida impregnada de beleza que conduz a descoberta do outro como um sujeito ao mesmo tempo igual e diferente) e se envolvem através de uma religiosidade traduzida pela irmandade do universo, que possibilita encontrar os fios que tecem a teia da vida (MEYER, 2008, p. 130).

No imprevisível corpo da natureza do sertão, tecido pelas relações e ligações de vidas distintas, expressam-se diversas maneiras de existência, fundamentadas na terra como um lugar ondenada está determinado. A jurema durante a aridez do verão mostra-se toda desfolhada, tendo, apenas, os galhos espinhosos expostos para o mundo, dando a impressão de estar morta; e em outros momentos, a mesma árvore veste-se de um verde encantador, e floresce lindas flores que exalam um perfume delicado. Os dois momentos distintos mostram a expressão do sertão de forma diversificada dizendo muito de um lugar que está sempre se transformando. Por isso, a vida, por intermédio da natureza do sertão, mostra-se por meio das antíteses elaboradas no viés de fazer-se presente e ocultar-se, mas sempre ligada pelos fios das partes distintas para uma comunhão do todo.

A vida esconde-se na mesma medida em que se realiza. Ao mesmo tempo em que se estende o domínio da totalidade, essa totalidade traduz-se por uma organização de partes distintas. A justaposição final resulta da integração inicial (MERLEAU-PONTY, 2006, p. 236). 
No sertão, a vida durante a seca não repousa na estática do nada, como se estivesse tudo morto, sem expressão e sem elaboração estética. Ao contrário, durante o verão a vida se reelabora, reinventa-se e se mostra de outra maneira, quando as árvores, outrora verde, desfolham-se, expressando uma nova forma, estendendo seus galhos para o horizonte vertical, como se fossem buscar água nas nuvens distantes, as quais poderiam amenizar sua existência nos dias de grande insolação. No mesmo painel das dificuldades diárias, o sertanejo busca como fazer diante de um mundo de incertezas em que se encontra. É um momento de procurar outras formas de convivências, criar técnicas de como cuidar da terra, aproveitando os lugares mais úmidos ou então a pouca água disponível. Mesmo acontecendo os ciclos de chuvas e seca, a cada estação, o sertanejo está sempre aprendendo, como se fosse a primeira vez.

Por não se expressar inteiramente, a natureza do sertão, constitui-se como algo que está sempre se revelando de forma indeterminada. $\bigcirc$ sertão mostra seus dois lados opostos, tanto o verão como o inverno, interligando e dimensionando-o como um todo. No período de chuvas, o seu corpo veste-se de um verde profundo, reflorescendo a caatinga, reaparecendo uma infinidade de animais, bem como fazendo o correr das águas nos riachos, grotões e rios; as lagoas transbordam e os açudes escoam as águas além do seu limite.

Durante o inverno, esperanças, grilos, pragas de gafanhotos e lagartas devoram as folhagens verdes. Crisálidas transformam-se em nuvens de borboletas multicores que, tremulando, voam em todas as direções. Presos aos galhos dos juazeiros, baraúnas, aroeiras e quixabeiras, velhos arapuás com suas abelhas de pernas serosas, sugam o néctar das flores silvestres, ao mesmo tempo em que realizam a polinização (NUNES FILHO, 2008, p. 32-33).

Quando chove, a existência do sertanejo se transforma. Surge, nesse período, a esperança de dias melhores e floresce na sua vida a satisfação e a alegria. $\bigcirc$ tempo é de mudança da natureza, e, junto a ela, o sertanejo se modifica, aprende sobre cada movimento da terra, de como deverá fazer para uma melhor plantação e colheita. Esse tempo torna o humano mais extrovertido, perceptivo com o movimento que explode na caatinga e nos outros animais.

Até agora tratamos de múltiplos encantamentos do sertão. Agora, o convidamos a junto conosco se aproximar um pouco mais de um aspecto que a pesquisa nos possibilitou compreender: as andanças do sertão. 


\section{O sertão é andante}

sertão anda na caminhada do sertanejo pelas interligações com o mundo vivido. O sertão é andante. Ele está em toda parte (ROSA, 200 1). Ele percorre os caminhos da subjetividade e se amplia como um espaço sem fronteiras pelo viés do sensível, fazendo pouso nas expressões estéticas do humano, dos outros animais e com a própria natureza como um todo. "A Natureza envolve tudo, minha percepção e a dos outros, enquanto estas só podem ser para mim um afastamento do meu mundo" (MERLEAU-PONTY, 2006, p. 45).

O sertão andante move-se pela configuração sensível de uma estética que eclode da paisagem e penetra no corpóreo humano. Esse contato é um quiasma de seres feitos do mesmo sentido de uma terra sempre aberta a espaços de compreensões diversas. Cada mover-se do sertão é a natureza manifestada na estética, ampliada na cultura, dando passos no viés do mundo vivido, revelando um logos estético de uma terra repleta de significações.

Mover-se para o mundo é a aproximação de vidas entrelaçadas para o sentido maior, desconstruindo a ideia de um mundo isolado ou na inércia. As expressões se movem, ganham significados e estão sempre se ampliando 206 e procurando outros sentidos. Isso faz o sertão tornar-se andante. Nele, mesmo estando fora do seu espaço geográfico, é possível perceber a expressão do sertanejo quando viaja para outras regiões. $O$ sertão revela a maneira de ser do humano, expressa seus gestos, formas de falar e de ser no mundo. Na subjetividade humana habita: os cantos dos pássaros, os sussurros da caatinga, os gemidos da seca, as explosões da natureza na invernada, os ecos dos vales e serras, o mungido do gado, as corridas de vaquejadas, o aboio durante o crepúsculo e outras infinidades de expressões, as quais são manifestações sensíveis, reveladas quando o sertanejo se encontra longe de sua terra. $\bigcirc$ sentir profundo do sertanejo, pelo sertão é o que o torna andante.

Aonde quer que eu vá, daquele lugar faço um 'boden' (terreno). Ligo o novo solo ao antigo que habitei. Pensar duas Terras é pensar uma mesma Terra. Para o homem, ali não pode haver senão homens: os animais, diz Husserl, são apenas variantes da humanidade. O que há de mais universal em nós, nós pensamos a partir do que temos de mais singular. O nosso solo amplia-se, mas não se desdobra-se, e não podemos pensar em referência a um solo de experiência desse gênero. A terra é a raiz da nossa história. 
Gilmar Leite Ferreira | Terezinha Petrucia da Nóbrega | Walter Pinheiro Barbosa Junior

Da mesma forma que a arca de Noé continha tudo que podia de restar de vivente e de possível, também a Terra pode ser considerada como portadora de todo possível (MERLEAU-PONTY, 2006, p. 1281.

Por intermédio da natureza, o sertão entranha-se na carne do sertanejo e faz o lugar ser andante, possibilitando a criação de avatares com outras terras, formando um só lugar na sua vida. Os dois lugares dialogam e ampliam a existência por meio de novas expressões e maneiras de ser. Mesmo em outras regiões, em outras culturas, o sertanejo, de forma imprecisa e espontânea, revela os caracteres do seu lugar de origem. É comum ouvir o dito popular que diz: fulano saiu do sertão, mas o sertão não saiu de dentro dele. $O$ mundo vivido é a história do humano consigo mesmo e com seu entorno, por intermédio das trocas de experiências e pelas relações de cumplicidade, dos paradoxos, configurando a existência para um sentido móvel de ser (MERLEAU-PONTY, 1999).

Merleau-Ponty (1999) afirma que o humano é um ser de percepção. Esse movimento dimensiona a existência sempre provocando no campo do sensível, expressões que dizem muito de si e do seu lugar. A interligação da interioridade e da exterioridade expande-se para uma revelação interagida de partes distintas. "Tudo o que se passa não se explica pela interioridade, nem pela exterioridade, mas por um acaso, que é a concordância entre esses dois lados, que é assegurada pela Natureza" (MERLEAU-PONTY, 2006, p. 129).

A natureza e a cultura, impregnadas na existência do sertanejo, é um livro aberto, mostrando os dizeres e fazeres do sertão, e levando a outros lugares, como a vida se dá numa terra tão complexa. A expressão do sertão, na existência do sertanejo, é um imenso caderno escrito e pintado com as cores da vida, sempre em desafio constante, e, por isso, tem muito o que ensinar.

aprendizado do sertanejo o faz cuidar da terra, como cuida do corpo. É uma aproximação sensível com a própria natureza, pois interliga as expressões da terra com as coisas do sentir. Esse estado modifica o humano, fazendo-o aprender com a natureza e manifestar de maneira afetuosa as relações constantes com o mundo vivido por meio da sua abertura para com os outros.

ser "aberto" em que nos tornamos, a existência que inventamos, a linguagem que socialmente produzimos, a história que fizemos e que nos faz, a cultura, a curiosidade, a indagação, a complexidade 
da vida social, as incertezas, o ritmo dinâmico de que a rotina faz parte mas não o reduz, a consciência do mundo que tem neste não eu e a de si como eu constituindo-se na relação contraditória com a objetividade, o 'ser programado para aprender', condicionado, mas não determinado, a imaginação, os desejos, os medos, as fantasias, a atração pelo mistério, tudo isso nos insere, como seres educáveis, no processo permanente de busca de que falei (FREIRE, 2007, p. 23).

Como podemos ler em Freire (2007), a constante busca do humano em fazer da vida um eterno aprendizado, de estar aberto ao mundo, faz-nos compreender as provocações constantes da natureza do sertão, que não se quieta mostra uma pedagogia tecida num contexto experiência vivenciada no sertão. Os passos incessantes do sertão estão sempre andando e deixando pegadas no corpo do sertanejo, num lugar sem porteiras e sem fronteiras.

\section{Considerações finais}

A partir de uma compreensão topográfica e móvel, podemos perceber que a educação do sertão não se limita ao seu espaço geográfico, como algo preso aos limites de fronteiras. O sertanejo é a expressão da educação do seu lugar; o sentimento de respeito e amor a terra; a aprendizagem que recebe dos outros animais, dos vegetais e da própria natureza como um todo. Na sua disposição sensivel de transformar os humanos, faz com que a educação do sertão se mova dentro do sentimento, abrindo as possibilidades de realização na expressão de um logos estético.

O fluxo vital é a explosão criativa da relação do sertanejo com o lugar em que vive. A cada momento, ele está aprendendo como cuidar da terra e se relacionar com outros seres vivos. Essa educação criativa provoca, na experiência vivida, a disposição sensível de estar atento aos movimentos da natureza; haja vista que eles não repetem e não se esgotam na sua totalidade, mas se tornam possivel de vivê-los.

Compreender a educação como um movimento, a algo que está sempre mostrando novas aprendizagens, remete-nos ao pensamento de Heráclito sobre as coisas não se repetirem. "Não podemos entrar duas vezes no mesmo rio; suas águas não são nunca as mesmas e nós não somos nunca os mesmos" 
(HERÁCLITO, 2002, p. 81 1). Cada movimento da educação traz aprendizados pelo motivo de asrelações entre os sujeitos estarem sempre se constituindo de novas experiências e de novos sentires.

sertão anda com as pernas do sentimento. Sua mobilidade de vida e existência sensível caminha dentro dos animais; mais especificamente do humano. $\bigcirc$ movimento do sertão mostra os símbolos, como: a vegetação, os animais, as manifestações culturais, sendo estas os cavaleiros andantes do sentimento sertanejo que galopam a sua existência por onde anda e vive. Por isso, o sertão não é, unicamente, uma ideia, como algo fechado em si mesmo, nem somente um espaço físico. Ele se mostra por meio de um estado de espírito, vindo da subjetividade e se manifesta na maneira de ser do sertanejo.

Na concepção de sempre se ocultar, o sertão não se mostra como uma terra dada por inteira. Sua revelação foge a ideia de ser um lugar onde podemos apreendê-lo, por meio do pensamento. Quanto mais nos aproximamos do sertão, mais ele escapa de uma conclusão final e mostra-se como um lugar onde sempre está no começo. Esse jeito do sertão se expressar estende sua maneira de ser para a construção de horizontes de sentidos, fazendo crer ser uma terra que, na sua complexidade, sempre tem algo a dizer de forma diferente, num movimento cada vez mais repleto de significados.

Na seca ou verão, quando se pensa que a vida não existe, e apenas a aridez é quem se faz presente, há uma expressão sensível do sertão e uma maneira singular dele tocar na existência do sertanejo. A caatinga seca estende-se quase que totalmente despida de folhagem, e o sertanejo torna-se uma pessoa que passa horas e horas a olhar para o horizonte esperando a chuva. Ele fica mais introspectivo e sensível ao mundo; não se transforma num humano revoltado, mas numa pessoa consciente dos momentos de transformação, possibilitando uma nova fartura de alimentos.

As secas se repetem, e os mesmos dramas são vividos. Não é pelo caminho de uma política de combate à seca, (como se fosse possível acabá-la), que irá resolver tal situação, pois ela sempre vem em determinados períodos, por isso é preciso uma política de convivência com a terra em sua diversidade. É válido colocar, em prática, de forma bem ampla, os projetos que levem mais desenvolvimento ao sertão, como: a construção de açudes, barragens externas e subterrâneas, perenização de rios, fabricação de poços, melhor distribuição dos recursos hídricos, melhores técnicas para a criação de animais e produção 
da agricultura, ou seja, a aplicabilidade de uma política que atenda a realidade sertaneja, sem assistencialismo e com respeito ao homem da terra, levando-se em consideração os saberes do homem do sertanejo. Assim, o cenário de vida difícil do sertão pode ser transformado.

Durante a época da aridez, a caatinga se veste de um branco cinzento, expressando uma estética que toca profundamente o espírito do homem sertanejo, influenciando a maneira de falar, de se expressar, de pensar a vida, de se relacionar consigo mesmo e com seu entorno. Nessa configuração, o sensível, (orgânico) e o mundo vivido se abraçam fenomenologicamente, numa só existência (MERLEAU-PONTY, 1999). O entrelaçamento do mundo vivido e sentido mostra o sertão como uma expressão diversa, apresentando o seu campo de configurações distintas.

A expressão assustadora da caatinga é temporal e mostra uma linguagem sensível que entrelaça o humano e o transforma para novas convivências pelo viés da relação de respeito e admiração que o sertanejo tem diante da natureza do sertão. Essa relação se fundamenta numa interação entre o humano e a natureza e forma o todo, um conjunto que engloba o mundo vivido, fazendo da experiência do sertanejo uma realização de aprendizados. Por isso, não

210 podemos conceber a natureza só a partir de algo isolado a título de conceitos dedutivos.

Embora tenhamos que reordenar o reino mineral, o vegetal e o animal, eles se constituem como um imenso conjunto da natureza do sertão por meio das relações objetivas e subjetivas. Essas relações expressam o ritmo da vida num complexo movimento, construído pelas indeterminações do que está sendo sempre elaborado e que nunca chega a um produto final. A natureza não é um todo-poderoso; Ela é um campo aberto para criação de si mesma, da elaboração sensível, que não se realiza numa finalidade, mas numa relação a qual diz muito do seu corpo, embora não se mostre por inteiro.

Indo ao sertão, como nos foi possível ir durante a pesquisa, no período da aridez profunda e, logo em seguida, visitá-lo durante o inverno vigoroso, percebemos a grande expressão de uma natureza imprevisível e repleta de transformações. A força da natureza, em transformar-se durante as primeiras chuvas, mostra como o sertão tem uma capacidade impressionante de se reconstituir de energias que supostamente estavam adormecidas. 
A pulsação da terra molhada, durante a invernada, agita cada célula, movimentando os desejos de amor a natureza. Esse momento seduz o sertanejo com seus encantos de beleza adentrando nos poros do corpóreo, fecundando a existência humana com os gametas da sedução e de uma natureza acasaladora.

Deslumbrado, o sertanejo sente-se em comunhão com a terra molhada durante a época de chuva. Na estação invernosa, podemos perceber o corpo da natureza e o do sertanejo configurando um estado de profunda excitação pelo viés da sensibilidade. As águas que beijam o solo da terra, fertilizando-a para a germinação das plantas, subjetivamente, são as mesmas que transbordam o açude do sentimento humano. Os orvalhos que escorrem e se acumulam no cálice das flores, ofertando o doce rocio aos beija-flores, abelhas e borboletas, são os mesmos pingos cristalinos que inundam os rostos felizes dos sertanejos nas manhãs invernosas do sertão. A terra repleta de um erotismo natural efecundante entrega-se aos afagos do sertanejo para realização da vida.

movimento da vida no sertão é um entrelaçamento constante de todas as formas de ser, e cada aprendizado do sertanejo, o vai transformando de acordo com os ritmos da terra. Nem é uma condição de causa e efeito, mas sim, é o todo da natureza atuando em suas partes, fazendo a vida se movimentar, abrindo um horizonte de significação constantemente, como se fosse sempre a primeira vez. Nesse sentido, a educação acontece carregada de encantos e de desafios, relacionando o sertanejo com seu lugar, transformando-o e possibilitando a compreensão que seu mundo encontra-se repleto de incertezas e aprendizados.

Depois de trilharmos as veredas sertanejas, de plantarmos e de colhermos no campo da reflexão filosófica e educacional, no curso de nossa pesquisa ao longo de três anos, apresentamos como resultado dos estudos, da atitude fenomenológica e da experiência vivida, a educação do sertão, que não pode se restringir a uma escola ou ser aprisionada em uma sala aula. Estamos retomando a tradição em que o homem vai se educando ao longo da vida, por meio de uma relação sensível com a natureza, com o ambiente social e com a cultura. São esses campos de aprendizagens que vão moldando a existência humana de acordo com a interação e a comunicação entre os seres vivos. 


\section{Notas}

1 Há sentido, mas esse sentido não se deixa 'pegar'; ele permanece fluido, tremulando numa leve ebulição. Um imenso e perpetuo rumorejo anima sentidos inúmeros que explodem, fulguram sem nunca tomar a forma definitiva de um signo sobrecarregado de significado; tema impossível, pois esse sentido idealmente trêmulo se vê impiedosamente recuperado por um sentido sólido (BARTHES, 2002).

$2 \bigcirc$ "Ser Selvagem" de Merleau-Ponty é o ser da criação; ele habita as interseções do corpo em movimento; o abismo das expressões inacabadas; o silêncio de cada gesto que grita; a linguagem muda que fala alto; o impensado, a arte que está sempre por se fazer; a estesia da experiência estética; a explosão metafísica da expressão criativa e o eclodir do ser no mundo (FERREIRA, 2010).

3 A expressão designa uma estrutura encontrada na fala, mas também no corpo vivo, na obra de arte, na coisa percebida, e que consiste na passagem mútua de um interior para um exterior e de um exterior para um interior ou no movimento mútuo de sair de si e de entrar em si. (DUPOND, 20111.

$4 \bigcirc$ Ser diz respeito ao ontológico, constituído como um único Ser e formado por vários seres (ABBAGNANO, 2007).

5 Nóbrega (Uma fenomenologia do corpo, 2010), Porpino (Dança é Educação, 2006), Medeiros (Uma Educação Tecida no Corpo, 2011 1).

6 Os signos são expressões culturais, sociais, ambientais e educacionais do sertão, que se fazem presentes na existência do sertanejo, entranhados na pele, nos músculos, ossos e pensamentos. São significações que dizem do lugar por meio dos fios da vida, tecidos pela natureza, impregnando e revelando sentidos e significados por meio da expressão do homem no mundo da vida (MERLEAU-PONTY, 1991).

7 Logos Estético é a razão sensível. É a maneira pela qual o homem se envolve, de maneira sensível, com as coisas do mundo, fundando uma razão estética, a partir da sua relação com o que the afeta, a qual pode ser uma obra de arte (MERLEAU-PONTY, 1999).

8 Merleau-Ponty (p. 85) distingue mundo de universo. $\bigcirc$ universo que a ciência constrói é "[...] uma totalidade acabada, explicita, onde as relações sejam de determinação recíproca" [...], ao passo que o mundo de nossa vida, meio de nossa experiência e de nossa ação, é "[...] uma multiplicidade aberta e indefinida, onde as relações são de implicação recíproca" (p. 381 ) (DUPOND, 2011 , p. 54-55).

9 A expressão mundo vivido é uma tentativa de tradução da expressão alemã lebenswelt, 0 lebenswelt ganha força com o entendimento da verdade, a partir da obra de Hurssel - investigações lógicas. Nesta, a verdade não pode ser definida como adequações do pensamento ao objeto, não sendo definida, a priori, pelo sujeito nem contemplada na pura exterioridade do objeto. (NÓBREGA, 2010).

10 conceito de quiasma recolhe a verdade fenomenológica da distinção entre o sentido da interioridade e o sentido de ser da exterioridade, recusando ao mesmo tempo considerá-los como separados ou separáveis (DUPOND, 2011 ). 
11 A fundação une dois termos numa relação recíproca entre fundante e fundado. É o que ocorre entre o fato e a razão, entre o tempo e a eternidade, a natureza e a história. A natureza "funda" a história e a cultura no sentido de que é a sua base ontológica (DUPOND, 2011 ).

12 Não falamos de símbolos abstratos, mas sim concretos: é a própria existência que é simbólica, é o próprio homem que é símbolo. O símbolo só é simbólico porque é constituído por essas realidades - humana - e não por outras. O símbolo insiste nas diversas maneiras de o sentido manifestar-se ou nos diversos sentidos em que há sentido (REZENDE, 1990,).

\section{Referências}

ABBAGNANO, Nicola. Dicionário de filosofia. São Paulo: Martins Fontes, 2007.

ALMEIDA, Maria da Conceição. Complexidade e ética como estética da vida. Revista Núcleo de Currículo: Comunicação e Cultura, Salvador, v. 1, n. 1, p. 7-25, jan./dez. 2000.

BARTHES, Roland. Roland Barthes por Roland Barthes. Tradução Leila Perrone-Moisés. São Paulo: Cultirx, 2002.

CHAUI, Marilena de Souza. Merleau-Ponty. São Paulo: Nova Cultural, 1989. IOs Pensadores).

CUNHA, Euclides da. Os Sertões. São Paulo: Nova Cultural, 2002.

DUPOND, Pascal. Vocabulário de Merleau-Ponty. Tradução Claudia Berliner. São Paulo, Martins Fontes, 2011.

FERREIRA, Gilmar Leite. Corpo e poesia: para uma educação dos sentidos. 2010. 143 f.Dissertação (Mestrado em Educação) - Programa de Pós-Graduação em Educação, Universidade Federal do Rio Grande do Norte, Natal, 2010.

FREIRE, Paulo. Política e educação. São Paulo: Villa das Letras, 2007.

HERÁCLITO.

CHAUÍ, Marilena de Souza. Introdução à história da filosofia. São Paulo: Companhia das Letras, 1994.

LÉVI-STRAUSS, Claude. Tristes trópicos. São Paulo: Companhia das Letras, 2000.

MEDEIROS, Rosie Marie Nascimento de. Uma dança tecida no corpo. São Paulo: Annablume, 2010. 
MELO, Adriana Ferreira. O lugar-sertão: grafias e rasuras 2004-2006). 2006. 131 f. Dissertação (Mestrado em Geografia) - Programa de Pós-Graduação em Geografia da Universidade Federal de Minas Gerais, Belo Horizonte, 2006.

MELLO FlLHO, Luiz Emygdio de. Caatinga, sertão, sertanejos. Uma visão da caatinga.Rio de Janeiro: Alumbramento/Livroarte, 1995.

MERLEAU-PONTY, Maurice. A natureza. Tradução Álvaro Cabral. São Paulo: Martins Fontes, 2006.

Fenomenologia da percepção. Tradução Carlos Alberto Ribeiro Moura. São Paulo: Martins Fontes, 1999.

O visível e o invisível. Tradução José Artur Gianotti e Armando Mora de Oliveira. São Paulo: Cosac \& Naify, 2000.

Signos. São Paulo: Martins Fontes, 1991.

MEYER, Mônica Ângela de Azevedo. Ser-tão natureza: a natureza em Guimarães Rosa. Belo Horizonte: Editora da Universidade Federal de Minas Gerais, 2008.

MORRIS, Desmond. O contrato animal. Tradução Lucia Simonini. Rio de Janeiro: Record, 2141990.

NÓBREGA, Terezinha Petrucia. Uma fenomenologia do corpo. São Paulo: Editora Livraria da Física, 2010.

NUNES FlLHO, Pedro. Cariris velhos: passando de passagem. Recife: Libert, 2008.

PORPINO, Karenine de Oliveira. Dança é educação: interfaces entre corporeidade e estética. Natal: Editora da Universidade Federal do Rio Grande do Norte, 2006.

REIS, Nayara Borges. Um sentido sensível do mundo na filosofia de Merleau-Ponty. Marília: Unesp, 2008. (v. 1, n. 1)

REZENDE, Antonio Muniz de. Concepção fenomenológica da educação. São Paulo: Cortez, 1990.

RONÁl, Paulo. Apresentação do livro grande sertão: veredas: Rio de Janeiro: Nova Fronteira, 2001.

ROSA, João Guimarães. Grande sertão: veredas. Rio de Janeiro: Nova Fronteira, 2001. 
Prof. Dr. Gilmar Leite Ferreira

Universidade Federal da Paraíba

Campus IV | Litoral Norte | Mamanguape | Paraíba

Departamento de Educação

Grupos de Pesquisa | Estesia, Corpo, Fenomenologia e Movimento I Sertania |

UFRN

E-mail | poetagilmar@gmail.com

Profa. Dra. Terezinha Petrucia da Nóbrega Universidade Federal do Rio Grande do Norte | Natal

Departamento de Educação Física

Programa de Pós-Graduação em Educação

Programa de Pós-Graduação em Educação Física Grupo de Pesquisa | Estesia, Corpo, Fenomenologia e Movimento,UFRN E-mail | pnobrega@ufrnet.br

Prof. Dr. Walter Pinheiro Barbosa Junior Universidade Federal do Rio Grande do Norte | Natal Departamento de Fundamentos e Políticas da Educação Programa de Pós-Graduação em Educação Grupo de Pesquisa | Sertania Consultor do Programa Nacional de Fortalecimento dos Conselhos Escolares | MEC E-mail | walterirnata|@hotmail.com

Recebido 7 jul. 2014 Aceito 6 ago. 2014 